\title{
Low-cost momentum strategies
}

Article

Accepted Version

Li, X., Brooks, C. and Miffre, J. (2009) Low-cost momentum strategies. Journal of Asset Management, 9 (6). pp. 366-379. ISSN 1470-8272 doi: https://doi.org/10.1057/jam.2008.28 Available at https://centaur.reading.ac.uk/36097/

It is advisable to refer to the publisher's version if you intend to cite from the work. See Guidance on citing.

Published version at: http://dx.doi.org/10.1057/jam.2008.28

To link to this article DOI: http://dx.doi.org/10.1057/jam.2008.28

Publisher: Palgrave Macmillan

All outputs in CentAUR are protected by Intellectual Property Rights law, including copyright law. Copyright and IPR is retained by the creators or other copyright holders. Terms and conditions for use of this material are defined in the End User Agreement.

\section{www.reading.ac.uk/centaur}

\section{CentAUR}

Central Archive at the University of Reading

Reading's research outputs online 
This is a post-peer-review, pre-copyedit version of an article published in the Journal of Asset Management. The definitive publisher-authenticated version X. Li, C. Brooks and J. Miffre, 'Low-Cost Momentum Strategies, Journal of Asset Management 9.6 (2009), pp.366-379 is available online at: http://www.palgrave-journals.com/jam/journal/v9/n6/abs/jam200828a.html 


\section{Low-Cost Momentum Strategies}

Xiafei Li

Cass Business School

City University

106 Bunhill Row

London EC1Y 8TZ

UK

e-mail: x.li-6@city.ac.uk

EDHEC Business School

393 Promenade des Anglais

06202

Nice

France

e-mail: Joelle.Miffre@edhec.edu

Tel: +33 (0)4 93183255
Chris Brooks

ICMA Centre

University of Reading

Whiteknights

PO Box 242

Reading RG6 6BA

UK

e-mail: c.brooks@,icmacentre.rdg.ac.uk

Tel: +44 (0)118 3788239

\section{Abstract}

The article analyses the impact of trading costs on the profitability of momentum strategies in the UK and concludes that losers are more expensive to trade than winners. The observed asymmetry in the costs of trading winners and losers crucially relates to the high cost of selling loser stocks with small size and low trading volume. Since transaction costs severely impact net momentum profits, the paper defines a new low-cost relative-strength strategy by shortlisting from all winner and loser stocks those with the lowest total transaction costs. While the study severely questions the profitability of standard momentum strategies, it concludes that there is still room for momentumbased return enhancement, should asset managers decide to adopt low-cost relative-strength strategies.

Key Words: Momentum profits, Transaction costs, Low-cost strategy

JEL: G12, G19 


\section{Introduction}

An increasing literature finds evidence that momentum strategies which buy stocks with the best past performance and sell stocks with the worst past performance generate significant abnormal returns (see Jegadeesh and Titman, 1993, 2001; Rouwenhorst, 1998; Chan, Jegadeesh and Lakonishok, 1996). The profitability of momentum strategies has also been shown to be predictable by a number of factors, such as the cross-sectional variation in expected returns, industry, trading volume, the business cycle, liquidity risk, time-varying unsystematic risk and trading costs (see, for example, Conrad and Kaul, 1998; Moskowitz and Grinblatt, 1999; Lee and Swaminathan, 2000; Chordia and Shivakumar, 2002; Li, Miffre, Brooks and O' Sullivan, 2008; Lesmond, Schill and Zhou, hereafter LSZ, 2004; Korajczyk and Sadka, 2004). Among these factors, trading cost is often regarded as one of the most important predictors.

The majority of early studies on momentum (Jegadeesh and Titman, 1993; Rouwenhorst, 1998; Moskowitz and Grinblatt, 1999; Liu, Strong and Xu, 1999) assume a round-trip cost of up to $2 \%$ and conclude that momentum profits are large enough to be exploited after taking trading costs into account. However, recent evidence has made it clear that the profitability of momentum strategies very much depends on the size and the constituents of transaction costs. Grundy and Martin (2001), for example, show that a round-trip cost in excess of $1.5 \%$ does wipe out the profitability of momentum strategies, a result questioned by Hanna and Ready (2005). LSZ (2004) explain that the losers, and to a lesser extent the winners, are heavily tilted towards off-NYSE stocks with small capitalization and low price, suggesting therefore that the long-short portfolios comprise stocks with low liquidity and high trading costs. ${ }^{1}$ Once these costs are taken into account, the alleged momentum profits disappear. Similarly, Korajczyk and Sadka (2004) conclude that equally- and valueweighted momentum strategies are profitable net of transaction costs for relatively small investment mandates only. Finally, Ali and Trombley (2006) relate momentum profits to short sales constraints and show that the later are important in explaining why momentum profits are not arbitraged away. Altogether, the evidence suggests that transaction costs are substantially higher than initially thought, calling into question the net profitability of relative-strength strategies.

We contribute to the literature on the impact of transaction costs on the profitability of long-short strategies in three ways. First, while the studies of LSZ (2004) and Hanna and Ready (2005) look at the net profits of one momentum strategy in the US, we analyze in this paper the robustness of their conclusions to 9 combinations of ranking and holding periods in the UK. Like LSZ (2004) for the US, we show for the UK that the loser portfolios, and to a lower extent the winner portfolios, are heavily tilted towards low capitalization stocks with low price and low trading volume. As a result, the average round-trip quoted spread for the losers are much higher than once thought $(3.76 \%)$ and greatly exceed those of the winners $(2.21 \%)$. When commissions, short selling costs and stamp duties are added, the average round-trip transaction cost

\footnotetext{
${ }^{1}$ Several US studies find that trading costs are associated with the market capitalization of stocks whereby small stocks have higher trading costs than large stocks (see Chan and Lakonishok, 1995, 1997; Bessembinder and Kaufman, 1997; Keim and Madhavan, 1997). For example, Chan and Lakonishok (1997) report that an average round-trip cost is $0.9 \%$ for large capitalisation stocks and $3.31 \%$ for small capitalisation stocks on the NYSE.
} 
based on the quoted spread rises to $3.77 \%$ for winners and $6.71 \%$ for losers. Once actual transaction costs are taken into account, the alleged momentum profits disappear.

Our second contribution relates to a detailed consideration of the reasons behind the relatively high trading costs of losers. We analyze the observed asymmetry in the trading costs of winners and losers by decomposing each round-trip trade into buyer- or seller-initiated trades. ${ }^{2}$ This seems important since a long position in a winner stock will necessarily end with the stock being sold when the long position is closed out. Similarly, a short position in a loser stock will necessarily end with that stock being bought back when the short position is closed. The distinction between buyer- and seller-initiated trades proves to be important as it sheds some light on the asymmetric pattern in transaction costs between winners and losers. Losers are more expensive than winners because of selling costs that are on average 2.3 times higher: selling a loser costs $2.67 \%$ on average, while selling a winner costs only $1.18 \%$. A closer analysis of the factors that impact the costs of buyer- and seller-initiated trades for winners and losers reveals that losers with low capitalization and low trading volume are particularly expensive to sell.

Our third contribution relates to a new type of relative-strength strategy. We term this a low-cost momentum strategy, which shortlists from the universe of winners and losers only the stocks with the lowest total trading costs - namely, the stocks that are the cheapest to trade. Based on actual turnover, low-cost relative-strength strategies that shortlist the $10 \%$ and $20 \%$ of winners and losers with the lowest total trading costs generate positive and significant net average returns of $18.24 \%$ and $15.84 \%$, respectively. The paper therefore severely questions the profitability of standard momentum strategies but concludes that there is still room for momentum-based return enhancement, should asset managers decide to adopt low-cost momentum strategies.

The rest of the study is organized as follows. Section II describes the data. Section III presents the methodology and some preliminary results on the relationship between size and transaction costs. The three following sections present our results with Section IV focusing on an extension of the LSZ (2004) to the UK, Section $\mathrm{V}$ analyzing the reason behind the asymmetry in trading costs between losers and winners and Section VI focusing on the low-cost momentum strategies that we propose. Finally, Section VII presents some concluding remarks.

\section{Data}

Our sample covers the period 31 December 1985 - 31 December 2005. All data are obtained from Primark Datastream. In order to avoid survivorship bias, we first construct a list of all the UK companies that were part of the London Share Price Database (LSPD) over the sample period. To avoid double counting of the companies in which the financial institutions invest, we exclude financial companies from our sample. To address concerns that momentum profits are solely driven by extremely small and illiquid stocks, we also exclude the lowest $5 \%$ of shares by market capitalization and companies with mid-prices that are less than $5 \mathrm{p}$.

2 A number of US studies report that stock prices respond differently between buyer- and seller-initiated trades (see Kraus and Stoll, 1972; Holthausen, Leftwich and Mayers, 1987; Chan and Lakonishok, 1993, 1995; Keim and Madhavan, 1996). 
As noted below, the momentum profits persist even after removing these extreme stocks. The treatment of dead stocks is as in Li, Miffre, Brooks and O'Sullivan (2008).

This process results in a cross-section of 3,520 companies for which we download information such as the intraday highest (ask) and lowest (bid) prices at the end of each month; the closing price adjusted for capital actions at the end of each month; the monthly market value; and the trading volume - that is, the number of shares that were traded at the end of the month. We also download the same information as above for each of the constituents of the FTSE 100 index and the Alternative Investment Market (AIM) index. The rationale for doing so is to analyze the impact of size on transaction costs in the UK and to compare the characteristics of the winner and loser stocks in terms of size, price and trading volume relative to those of the constituents of a large capitalization index (the FTSE 100 index) and a small capitalization index (the AIM index).

\section{Methodology Used to Estimate Trading Costs}

Our analysis of transaction costs includes the bid-ask spread (estimated based on quoted spread and effective spread), commissions, stamp duties and short-selling costs. The estimation procedure is explained below.

\section{Quoted Spread Estimate}

The quoted bid-ask spread is the simplest measure of trading costs. It is measured as the difference between the quoted ask and bid prices. Following Chordia, Roll and Subrahmanyam (2000), we measure the proportional quoted spread as

$$
\text { Quoted Spread }=100 \times\left(\frac{P_{A i t}-P_{B i t}}{P_{M i t}}\right)
$$

where $P_{A i t}$ is the ask price, $P_{B i t}$ is the bid price and $P_{\text {Mit }}$ is the bid-ask midpoint for asset $i$ on the last trading day of month $t$. The quoted spread measures the percentage trading cost incurred in a round-trip trade. ${ }^{3}$

\section{Effective Spread Estimate}

The effective spread is the difference between the transaction price and bid-ask midpoint. Lee and Ready (1991) argue that quoted spreads may overstate actual trading costs. The effective bid-ask spread is supposed to provide a more accurate measure of actual trading costs than the quoted spread since it accounts for potential price improvement when market orders are crossed or when specialists "stop" their orders before trades take place. Following LSZ (2004), the proportional half effective spread is calculated as

$$
\text { Half effective spread }=100 \times\left(\frac{P_{i t}-P_{M i t}}{P_{M i t}}\right)
$$

where $P_{i t}$ is the transaction price for asset $i$ on the last trading day of month $t$. We follow the algorithm introduced by Lee and Ready (1991) to classify buyer- or seller-initiated trades. The trade is defined as seller-

${ }^{3}$ Due to reporting errors, we filter out and remove stocks with negative quoted spreads and those with quoted spreads greater than $100 \%$. This helps us mitigate the problem of having estimates of trading costs driven by a few winner and loser stocks with extremely high or low spreads. 
initiated when the transaction price is less than the bid-ask midpoint while it is defined as buyer-initiated when the transaction price is larger than the bid-ask midpoint. The half effective spread measures the percentage trading cost paid in a one-way trade. We compute a round-trip effective spread as the absolute half effective spread for a buyer-initiated trade plus the absolute half effective spread for a seller-initiated trade.

\section{Commissions, Stamp Duties and Short-Selling Costs}

Bid-ask spread is not the only cost associated with trading stocks. Equity investors must pay brokerage commissions as well as certain fees and stamp duties. Commission is measured as a percentage of the total trade value and it generally decreases as the total trade value increases. The following commission charges schedule was obtained from Barclays Stockbrokers ${ }^{4}$ for company dealing accounts: transaction value $\AA^{0}$ -

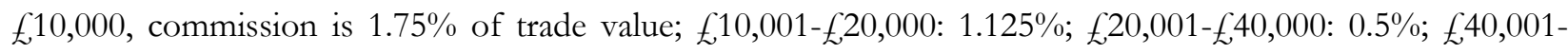

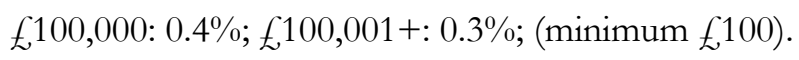

Aside from commissions, we also consider stamp duty (payable at the rate of $0.5 \%$ at the time of dealing on all UK equity purchases) and short-selling costs. Accounting for the impact of short-selling costs on the size of the momentum profits is critical since many studies (among others, Moskowitz and Grinblatt, 1999; Hong, Lim and Stein, 2000; Ali and Trombey, 2006) suggest that the momentum effect is mainly driven by the losers. We assume a short-selling cost of $1.5 \%$ per year, an estimate that is similar to the cost levied by Barclays Stockbrokers. We assume throughout that traders can short-sell loser stocks when they see it fit. While the uptick rule previously forbade US traders from short selling on a downtick, the Financial Service Authority has never ruled against the practice in the UK. Since short-selling losers is allowed in the UK and was forbidden on a downtick in the US, ${ }^{5}$ our UK-based momentum strategy is replicable, while the returns reported in the US over the same period can only be regarded as "paper" profits.

\section{Net Momentum Returns: Evidence from the UK}

\section{The Momentum Strategies}

This section extends to the UK the analysis of LSZ (2004) for the US. We analyze the magnitude of trading costs and measure the net profits of 9 relative-strength strategies. All stocks are ranked and sorted into 10 portfolios based on their past $J$-month cumulative returns $(J=3,6,12$ months). The decile portfolio with the highest cumulative return is termed the "winner" portfolio, while the decile portfolio with the lowest cumulative return is called the "loser" portfolio. The return on the momentum portfolio is then measured as the return difference between the winner and loser portfolios over the next $K$ months ( $K=3,6,12$ months). The resulting strategy is called the $J-K$ momentum strategy. The procedure is rolled forward at the end of each holding period to produce new winner, loser and momentum portfolios. The formation of the relativestrength portfolios is therefore non-overlapping, thus reducing the trading frequency and the transaction costs incurred in portfolio construction. The stocks in the winner and loser portfolios are equally weighted. A valueweighting scheme would allocate more wealth to larger, more liquid stocks and thus would have been less

\footnotetext{
${ }^{4}$ http:/ / www.stockbrokers.barclays.co.uk/?category=whatweoffer\&usecase=landing 48

5 The up-tick rule was initially established in 1938 but was abandoned in June 2007 following a gradual reduction in the scope of securities covered. However, the rule applied to all US equities for most of our sample period.
} 
costly, although the net returns to the value weighted portfolios are lower. ${ }^{6}$ On balance, however, we choose an equal-weighting scheme in order to be consistent with the existing literature (Jegadeesh and Titman, 1993, 2001; Hong, Lim and Stein, 2000; LSZ, 2004).

\section{The Impact of Trading Costs on Momentum Profits}

While implementing a momentum strategy, investors are likely to face significant trading costs. First, the momentum portfolios are heavily weighted toward small stocks with low price and low trading volume and these stocks are relatively more expensive to trade. Second, the momentum strategies are highly trading intensive: investors must buy the winners and short sell the losers at the end of the ranking period and close their long-short positions by selling the winners and buying back the losers at the end of the holding period. This requires up to four round-trip trades a year for strategies with 3-month holding period, up to two roundtrip trades a year for strategies with 6-month holding period and up to one round-trip trade a year for strategies with 12-month holding period. As a first approximation, the annual execution cost of a 3-month momentum strategy might be four times higher than that of a strategy with a 12-month holding period.

Assuming a 100\% turnover of the portfolios, the average round-trip quoted spreads are found to be equal to $2.21 \%$ for the winners and $3.76 \%$ for the losers. Once round-trip commissions, stamp duties and short selling costs are added, round-trip transaction costs equal on average $3.77 \%$ for winners and $6.71 \%$ for losers. Early studies on momentum strategies (Jegadeesh and Titman, 1993; Rouwenhorst, 1998; Moskowitz and Grinblatt, 1999) assume round-trip transaction costs below $2 \%$ for both winners and losers. We find that this estimate vastly underestimates actual trading costs. Assuming, as previously reported, symmetric costs on long and short positions will also lead to a severe overstatement of net momentum returns.

The round-trip quoted and effective spreads are $2.21 \%$ and $1.90 \%$ respectively for the winners and $3.76 \%$ and $3.72 \%$ for the losers. A comparison of these costs to the average quoted and effective spreads of the constituents of the FTSE 100 and AIM indices suggests that the average quoted spread of the winners is comparable to that of the constituents of the FTSE 100 index $(2.22 \%)$, while the average effective spread of the winners slightly exceeds that of the FTSE 100 (1.26\%). While the assumption made in previous studies of an equal spread between the large capitalization index and the winners seems to be valid, this assumption breaks down for the losers. Their quoted and effective spreads resemble much more the ones reported for the AIM index $\left(3.98 \%\right.$ and $2.38 \%$, respectively). ${ }^{7}$

It could be assumed that the entire constitution of the momentum portfolio is fully turned over at the end of every period. However, in reality, momentum traders do not need to close out their entire positions at the end of the holding period as some stocks will stay in the winner and loser portfolios from one holding period to

\footnotetext{
${ }^{6}$ We also examine the gross and net profitability of value-weighted momentum portfolios. The larger weights on big cap stocks slightly degrades the performance of the strategies but our key findings are unaltered. These results are not shown but are available from the authors on request.

${ }_{7}$ The reported trading costs are measured at the end of the ranking period. In reality, while the positions are opened at the end of the ranking period, they are closed at the end of the holding period. We found that the quoted and effective spreads reported for winners and losers are not sensitive to the time the position is closed.
} 
the next. If the momentum strategy recommends retaining the stocks in the following period, trading costs are not actually incurred since there is no need to close the initial position and to re-open a new one. We find that strategies with long ranking periods and short holding periods have high proportions of stocks remaining in the long-short portfolio in the following holding period. ${ }^{8}$ For instance, the 12-3 strategy recommends on average to keep a long (short) position in 53.83\% (58.6\%) of the winners (losers) in the following period. This implies that on average only $46.17 \%$ of the winners and $41.4 \%$ of the losers need to change hands at end of holding period. Other things being equal, the 12-3 strategy calls for less rotation in the constituents of the long-short portfolio and is therefore cheaper to implement. At the other end of the spectrum, the longer the holding period is, the more likely it is that the constituents of the long-short portfolios will change hands in the next holding period. For example, the 6-12 strategy recommends that only $11.85 \%$ of the winners and $15.57 \%$ of the losers be retained at the end of the holding period.

Table 1 reports annual momentum returns and net momentum profits after taking account of total trading costs based on full and actual turnovers. All momentum strategies produce significant positive gross returns, with an average return of $23.14 \%$ per year across the 9 strategies. However, the picture is completely different once transaction costs are taken into account. Based on full turnover, none of relative-strength strategies generate positive and significant net profits. The strategies with short holding periods even yield significant negative net average returns at the $5 \%$ level. Once we employ the lower and more realistic measure of trading costs based on actual turnover, the net momentum returns are either indistinguishable from zero or negative (for the 3-3 strategy). In summary, the magnitude of trading costs plays an important role in assessing the profitability of momentum strategies. When trading costs are considered, none of the momentum strategies generates a positive net return.

\section{Analysis of the Observed Asymmetric Costs of Winners and Losers}

The results thus far show that trading costs are asymmetric for the winners and losers, with the losers having higher trading costs than the winners. This section studies further the observed asymmetry by splitting each round-trip winner and loser trade into buyer-initiated trade and seller-initiated trades. As previously mentioned, the trade is defined as seller-initiated if the transaction price is less than the bid-ask midpoint; if not, it is defined as buyer-initiated. The rationale for splitting each round-trip trade into two one-trip trades comes from the fact that buyer- and seller-initiated trades have been found to have different impacts on prices (see Kraus and Stoll, 1972; Holthausen, Leftwich and Mayers, 1987; Chan and Lakonishok, 1993, 1995; Keim and Madhavan, 1996). So an analysis of the one-trip effective spread might shed more light on the reasons behind the observed asymmetry between the transaction costs of winners and losers.

Figure 1 shows the average estimates of the half effective spreads on buyer- and seller-initiated trades for 3 winner portfolios, 3 loser portfolios, ${ }^{9}$ and the average constituent of the FTSE 100 and AIM indices. It is clear that buying the average constituent of the FTSE100 index costs as much as selling it $(0.63 \%$ and $0.64 \%$,

\footnotetext{
8 These results are not tabulated here but are available from the authors on request.

9 The results from strategies other than with 12-month holding period are similar and are available from the authors upon request.
} 
respectively). This conclusion does not, however, apply to small capitalization stocks, for which a sellerinitiated trade on average costs $1.72 \%$, which is 2.6 times as much as a buyer-initiated trade (which costs $0.66 \%$ on average). Likewise, the half effective spreads of seller-initiated trades are larger than the half effective spreads of buyer-initiated trades for both losers and winners. For example, buying a winner only costs $0.88 \%$ on average, while closing a long position in a winner costs slightly more $(1.18 \%)$. The difference between the costs of buyer- and seller-initiated trades is even more pronounced for losers which happen to be extremely expensive to sell: selling a loser costs a massive $2.67 \%$ on average, while buying it back only costs $1.14 \% .{ }^{10}$ While buying winners is only slightly less expensive than buying losers $(0.88 \%$ and $1.14 \%$, respectively), the selling costs of winners and losers dramatically differ (1.18\% and $2.67 \%$, respectively). Clearly, the difference in trading costs that we observed between winners and losers can be explained by the fact that the losers are particularly expensive to sell.

The results in Figure 1 for representative constituents of the FTSE100 and AIM indices show that the magnitude of the costs of seller-initiated trades depends on the market capitalization of the stock that is being traded. The smaller the stock, the more expensive it is to sell. This observation motivates our analysis of the relationship between transaction costs on buyer- and seller-initiated trades and the size of the winners and losers. To do that, we first sort the universe of stocks into winners and losers based on their past performance using, as previously, the $10 \%$ and $90 \%$ breakpoints. We then split each of the two extreme performers into three sub-portfolios based on the average market capitalization of the stock in the ranking period. We use the 30\%-70\% breakpoints and end up with 3 winner portfolios (Small-Winner, Medium-Winner and Big-Winner) and 3 loser portfolios (Small-Loser, Medium-Loser and Big-Loser).

Figures 2 and 3 report for different levels of market capitalization the average half effective spreads of buyerand seller-initiated trades for the 3 winner and 3 loser portfolios with 12-month holding period. As reported for the FTSE100 and AIM indices in Figure 2, size does not have much impact on the cost of buying losers and winners. Buying small capitalization stocks costs on average $0.92 \%$ for winners and $1.26 \%$ for losers; buying large capitalization stocks costs on average $0.81 \%$ for winners and $1.07 \%$ for losers. So we can safely conclude that the market capitalization of a stock is not an important determinant of the cost of a buyerinitiated trade. The opposite conclusion applies to seller-initiated trades, for which we find an inverse relationship between size and costs. Indeed, selling small capitalization stocks on average costs $1.67 \%$ for winners and $4.80 \%$ for losers. The costs of selling large capitalization stocks is much lower $(0.84 \%$ for winners and $1.57 \%$ for losers). We can therefore conclude that the difference in transaction costs between losers and winners that we observed earlier on is driven at least in part by small capitalization loser stocks that are extremely expensive to sell.

\section{The Profitability of Low-Cost Momentum Strategies}

\footnotetext{
${ }^{10}$ Our results are consistent with Berkowitz, Logue and Noser (1988) who argue that the relatively higher cost of sells might be due to them being motivated by information and done in larger volumes and at greater speed than buys. Keim and Madhavan (1997) also report that the total cost of seller-initiated trades are larger than those of buyer-initiated trades and also attribute this finding to order quantities that are larger for sells than for buys in their sample.
} 
Our previous results provide evidence that the profitability of momentum strategies is strongly impeded by trading costs. This motivates us to exploit a new type of momentum strategy with low trading costs. We call it a low-cost momentum strategy. The idea is to shortlist from of the universe of losers and winners the stocks that are likely to be the cheapest to trade. The strategy first ranks all stocks into 10 equally-weighted groups based on their past $J$-month cumulative returns $(J=3,6,12$ months). The $10 \%$ of all stocks with high cumulative returns are defined as winner stocks, and the $10 \%$ of all stocks with low cumulative returns are defined as loser stocks. Our low-cost momentum strategy then buys the $L \%(L \%=10 \%, 20 \%, 50 \%, 80 \%$ and $90 \%$ ) of winners, sells the $L \%$ of losers that have the lowest total costs (measured as quoted spread plus commission) and holds the long-short portfolio over the next $K$ months ( $K=3,6$ and 12 months). We call the ensuing strategy the $J-K-L \%$ strategy. The resulting combination of ranking periods, holding periods and transaction costs result in a total of 45 low-cost strategies. We conduct here the same analysis as previously and analyze the net profits of the 45 low-cost strategies based on full and actual turnover.

Table 2 presents, for each of the 45 low-cost strategies, the mean proportions of winner and loser stocks that are retained in the same portfolio in the following holding period, along with estimates of total trading costs based on actual turnover. The results show that the lower $L$, the more likely it is that the constituents of the long-short portfolio will change hands from one holding period to the next. Across the 9 strategies for which $L=10 \%$, only $5.62 \%$ of winners and $8.35 \%$ of losers are retained in the long-short portfolios on average from one holding period to the next. When $L=90 \%$, the proportion of retained positions is much higher (at $20.77 \%$ for winners and $23.97 \%$ for losers on average). It follows that there might be a trade-off between holding fewer stocks and rotating the portfolio more often.

Table 2 shows that the 12-3 relative-strength strategy involves the least trading activity since it retains the highest proportions of winners and losers from one holding period to the next. For example, 31.14\% (34.01\%) of the time, the winners (losers) of the 12-3-50\% strategy will remain in the winner (loser) portfolio in the following holding period. This suggests that based on full turnover implementing the $12-3-50 \%$ lowcost strategy can save over $30 \%$ of the costs involved on the purchase and sale of winners and losers. As a result, the total trading costs based on actual turnover of the 12-3 strategy drop from $19.27 \%$ (on an annualized basis) for the standard momentum strategy in Table 1 to $10.10 \%$ and $10.94 \%$ in Table 2 for the 12 $3-10 \%$ and $12-3-20 \%$ low-cost strategies, respectively. Overall, based on actual turnover, the low-cost momentum strategies that shortlist from the universe of winners and losers the $10 \%$ or $20 \%$ of stocks with the lowest transaction costs are much less expensive than the standard momentum strategies of Table 1. Across the $9 \mathrm{~J}$ - $\mathrm{K}$ strategies the average yearly trading cost for $L=10 \%$ is only $7.04 \%$ versus $7.79 \%$ for $L=$ $20 \%$ and $17.80 \%$ for $L=100 \%$ (in Table 1). So our low-cost strategies can reduce the total trading costs of standard momentum strategies by up to $60 \%$.

Table 3 reports the net annual returns on low-cost relative-strength strategies once total trading costs based on full and actual turnovers are taken into account. While none of the standard momentum strategies generate positive net returns at the $5 \%$ level in Table 1, Table 3 shows that based on full turnover, 31 out of 45 low- 
cost strategies offer positive and significant net returns at the $5 \%$ level. When actual turnover is considered instead, 35 low-cost strategies have positive net returns at the 5\% level. ${ }^{11}$ The $12-12-10 \%$ low-cost strategy happens to be the most profitable $(2.16 \%$ net monthly return based on actual turnover, $t$-statistic of 4.13$)$. The $3-3-90 \%$ strategy is the least profitable (average monthly net return of $-0.62 \%$ based on actual turnover, $t$ statistic of -1.78). The performance of the strategies that shortlist the most liquid $10 \%$ and $20 \%$ winners and losers is particularly noticeable. Based on actual turnover, the strategies with $L=10 \%$ and $L=20 \%$ generate average net returns of $18.24 \%$ and $15.84 \%$, respectively.

\section{Conclusions}

The article examines the profitability of momentum strategies in the $\mathrm{UK}$, taking into account the transactions costs involved in executing the required trades. We corroborate for nine momentum strategies in the UK the conclusions of LSZ (2004) for the 6-6 momentum strategy in the US. In particular, we find that losers have lower market capitalization, lower price and lower trading volume than winners and, thus, higher total costs. An average round-trip quoted spread equals $2.21 \%$ for winners and $3.76 \%$ for losers. Based on effective spreads, round-trip transaction costs are only marginally smaller (1.90\% for winners and $3.72 \%$ for losers). Once commissions, short selling costs and stamp duties are added, the average round-trip transaction cost based on the quoted spread rises to $3.77 \%$ for winners and $6.71 \%$ for losers. These estimates are far from the $2 \%$ round-trip cost reported in the early momentum literature which severely underestimated the actual cost of trading both losers and winners. Net of these costs based on full or actual turnover, the profitability of relative-strength strategies proves to be an illusion.

Aside from providing confirmatory evidence for a range of momentum portfolios for the UK, we add our own contribution to the LSZ (2004) study in two ways. First, we investigate the reasons for the observed asymmetric pattern in trading costs between winners and losers by splitting each round-trip trade into a buyerinitiated trade and a seller-initiated trade. While the trading costs of buyer-initiated trades are almost the same for winners and losers, the trading costs of seller-initiated trades are asymmetric. On average, selling losers costs 2.3 times as much as closing a position in winners. This suggests that the asymmetry in trading costs between winners and losers critically relates to the higher costs of selling the latter. We also relate the costs of buyer- and seller-initiated trades to the size and trading volume of winners and losers. We find that the asymmetry in trading costs between winners and losers is due to the higher cost of selling small capitalization loser stocks with low trading volumes. We note also that while size critically impacts the cost of selling winners and losers, it does not affect the cost of buying them. Finally, for both winners and losers, trading volume relates positively to the cost of buyer-initiated trades and negatively to the cost of seller-initiated trades.

Second, we derive and test the profitability, net of transaction costs, of so-called low-cost momentum strategies that shortlist from the universe of winners and losers the stocks with the lowest total transaction

\footnotetext{
11 The low-cost momentum strategies are profitable on a risk-adjusted basis too. Estimates from the market model or the three-factor model of Fama and French (1993) are available upon request from the authors.
} 
costs. Interestingly, we conclude that, although standard momentum strategies are not profitable net of transaction costs, 35 out of 45 low-cost strategies produce, based on actual turnover, positive and significant net average returns. For example, the strategies that shortlist the $10 \%, 20 \%$ and $50 \%$ of winners and losers with the lowest total transaction costs generate average net returns of $18.24 \%, 15.84 \%$ and $12.49 \%$, respectively. The paper therefore severely questions the profitability of standard momentum strategies but concludes that there is still room for momentum-based return enhancement, should asset managers decide to adopt low-cost momentum strategies.

\section{References}

Ali, A., and M. A. Trombley (2006) 'Short Sales Constraints and Momentum in Stock Returns', Journal of Business Finance and Accounting 33, 3-4, 587-615.

Bessembinder, H., and H. M. Kaufman (1997) 'A Comparison of Trade Execution Costs for NYSE and NASDAQ-Listed Stocks', Journal of Financial and Quantitative Analysis 32, 287-310.

Berkowitz, S. A., D. E. Logue and Eugene A. Noser (1988) 'The Total Cost of Transactions on the NYSE', Journal of Finance 43, 1, 97-112.

Chan, L. K. C., N. Jegadeesh, and J. Lakonishok (1996) 'Momentum Strategies', Journal of Finance 51, 1681 1713.

Chan, L. K. C., and J. Lakonishok (1993) 'Institutional Trades and Intraday Stock Price Behavior', Journal of Financial Economics 33, 173-199.

Chan, L. K. C., and J. Lakonishok (1995) 'The Behavior of Stock Prices Around Institutional Trades', Journal of Finance 50, 1147-1174.

Chan, L. K. C., and J. Lakonishok (1997) 'Institutional Equity Trading Costs: NYSE versus Nasdaq', Journal of Finance 52, 713-735.

Chordia, T., R. Roll, and Avanidhar Subrahmanyam (2000) 'Commonality in Liquidity', Journal of Financial Economics 56, 3-28.

Chordia, T., and L. Shivakumar (2002) 'Momentum, Business Cycle, and Time-varying Expected Returns', Journal of Finance 57, 985-1018.

Conrad, J., and G. Kaul (1998) 'An Anatomy of Trading Strategies', Review of Financial Studies 11, 489-519.

Fama, E. F., and K. R. French (1992) 'The Cross-section of Expected Stock Returns', Journal of Finance 47, 427-465.

Fama, E. F., and K. R. French (1993) 'Common Risk Factors in the Returns on Stocks and Bonds', Journal of Financial Economics 33, 3-56.

Grundy, B. D, and J. S. Martin (2001) 'Understanding the Nature of the Risks and the Source of the Rewards to Momentum Investing', Review of Financial Studies 14, $29-78$.

Hanna, J. D., and M. J. Ready (2005) 'Profitable Predictability in the Cross Section of Stock Returns', Journal of Financial Economics 78, 463-505.

Holthausen, R., R. Leftwich, and D. Mayers (1987, The Effect of Large Block Transactions on Security Prices, Journal of Financial Economics 19, 237-267.

Hong, H., T. Lim, and J. C. Stein (2000) 'Bad News Travels Slowly: Size, Analyst Coverage, and the Profitability of Momentum Strategies', Journal of Finance 55, 265-295.

Jegadeesh, N., and S. Titman (1993) 'Returns to Buying Winners and Selling Losers: Implications for Stock Market Efficiency', Joumal of Finance 48, 65-91.

Jegadeesh, N., and S. Titman (2001) 'Profitability of Momentum Strategies: An Evaluation of Alternative Explanations', Journal of Finance 56, 699-720.

Keim, D. B., and A. Madhavan (1995) 'Anatomy of the Trading Process: Empirical Evidence on the Behavior of Institutional Traders', Journal of Financial Economics 37, 3, 371-398.

Keim, D. B., and A. Madhavan (1996) 'The Upstairs Market for Large-Block Transactions: Analysis and Measurement of Price Effect', Review of Financial Studies 9, 1-36.

Keim, D. B., and A. Madhavan (1997) 'Transaction Costs and Investment Style: An Inter-exchange Analysis of Institutional Equity Trades', Journal of Financial Economics 46, 265-292.

Korajczyk, R. A., and R. Sadka (2004) ‘Are Momentum Profits Robust to Trading Costs?’ Journal of Finance 59, 1039-1082.

Kraus, A., and H. Stoll (1972) 'Prices Impacts of Block Trading on the New York Stock Exchange', Journal of Finance 27, 569-588. 
Lee, C. M. C., and M. J. Ready (1991) 'Inferring Trade Direction from Intraday Data', Journal of Finance 46, 733-746.

Lee, C. M. C., and B. Swaminathan (2000) 'Price Momentum and Trading Volume', Journal of Finance 55 (20172069.

Lesmond, D. A., M. J. Schill, and C. Zhou (2004) 'The Illusory Nature of Momentum Profits', Journal of Financial Economics 71, 349-380.

Li, X., J. Miffre, C. Brooks, and N. O' Sullivan (2008) 'Momentum Profits and Time-Varying Unsystematic Risk', Journal of Banking and Finance 32, 4, 541-558

Liu, W., N. Strong, and X. Xu (1999) 'The Profitability of Momentum Investing', Journal of Business Finance and Accounting 26, 1043-1091.

Moskowitz, T. J., and M. Grinblatt (1999) 'Do Industries Explain Momentum?' Journal of Finance 54, 1249 1290.

Rouwenhorst, K. G. (1998) 'International Momentum Strategies', Journal of Finance 53, 267-284. 
Table 1 - Annualized Estimates of Gross and Net Returns on Momentum Strategies

The table reports annual mean gross and net returns (\%) on momentum strategies based on full and actual turnovers. The estimates of total trading costs based on quoted spread (\%) equal quoted spread plus commission, stamp duty on purchases $(0.5 \%$ per purchase) and short selling costs for losers $(1.5 \%$ per year). The estimates of total trading costs based on effective spread (\%) equal effective spread plus commission, stamp duty on purchases and short selling costs for losers. $t$-statistics in parentheses; "annual momentum return" shows the gross returns.

\begin{tabular}{|c|c|c|c|c|c|c|}
\hline \multirow[b]{2}{*}{ Turnover } & \multicolumn{2}{|c|}{$\begin{array}{c}\text { Holding period of } 3 \\
\text { months }\end{array}$} & \multicolumn{2}{|c|}{$\begin{array}{l}\text { Holding period of } 6 \\
\text { months }\end{array}$} & \multicolumn{2}{|c|}{$\begin{array}{l}\text { Holding period of } 12 \\
\text { months }\end{array}$} \\
\hline & Full & Actual & Full & Actual & Full & Actual \\
\hline \multicolumn{7}{|c|}{ Panel A: Ranking period of 3 months } \\
\hline Annual momentum return & $\begin{array}{l}19.46 \\
(4.78)\end{array}$ & & $\begin{array}{l}22.22 \\
(4.31)\end{array}$ & & $\begin{array}{l}22.05 \\
(2.32)\end{array}$ & \\
\hline \multicolumn{7}{|l|}{ Net return after total trading cost } \\
\hline Based on quoted spread & $\begin{array}{l}-21.07 \\
(-5.59)\end{array}$ & $\begin{array}{l}-14.69 \\
(-3.87)\end{array}$ & $\begin{array}{c}1.37 \\
(0.28)\end{array}$ & $\begin{array}{c}4.05 \\
(0.84)\end{array}$ & $\begin{array}{c}9.31 \\
(0.92)\end{array}$ & $\begin{array}{l}11.25 \\
(1.17)\end{array}$ \\
\hline Based on effective spread & $\begin{array}{l}-19.43 \\
(-5.15)\end{array}$ & $\begin{array}{l}-13.26 \\
(-3.49)\end{array}$ & $\begin{array}{c}2.24 \\
(0.47)\end{array}$ & $\begin{array}{c}4.83 \\
(1.01)\end{array}$ & $\begin{array}{c}9.60 \\
(0.96)\end{array}$ & $\begin{array}{l}11.44 \\
(1.20)\end{array}$ \\
\hline
\end{tabular}

Panel B: Ranking period of 6 months Annual momentum return

$\begin{array}{cccccc}26.15 & & 25.74 & & 21.10 & \\ (5.50) & & (4.96) & & (2.37) & \\ & & & & & \\ -13.77 & 0.78 & 5.18 & 8.10 & 8.79 & 10.40 \\ (-2.95) & (0.17) & (1.04) & (1.62) & (1.01) & (1.10) \\ -12.16 & 1.85 & 5.79 & 8.64 & 9.24 & 10.77 \\ (-2.71) & (0.41) & (1.19) & (1.76) & (1.08) & (1.17)\end{array}$

Net return after total trading cost

Based on quoted spread

Based on effective spread

Net return after total trading cost

$\begin{array}{cc}4.54 & 10.17 \\ (0.79) & (1.76) \\ 4.97 & 10.49 \\ (0.89) & (1.85)\end{array}$


Table 2 - Percentage of Positions Retained and Estimates of Monthly Trading Costs Based on Actual Turnover - Results for Low-Cost Momentum Strategies

The table reports estimates of annual total trading costs (\%) for various low-cost momentum strategies based on actual turnover. Winner and Loser are equally-weighted non-overlapping portfolios containing $L \%(L=10,20$, 50, 80 and 90) of winner and loser stocks with the lowest total costs (measured as quoted spread plus commission). When actual turnover is measured, stamp duty on purchases $(0.5 \%$ per purchase) and short selling costs for losers $(1.5 \%$ per year) are also considered as part of trading costs. Momentum is a portfolio that buys the resulting winners and short sells the resulting losers. "Portfolio position retained" is the mean ratio of winners and losers that remain in the respective portfolios in the following period.

\begin{tabular}{|c|c|c|c|c|c|c|c|c|c|}
\hline \multirow{2}{*}{ 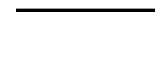 } & \multicolumn{3}{|c|}{ Holding period of 3 months } & \multicolumn{3}{|c|}{ Holding period of 6 months } & \multicolumn{3}{|c|}{ Holding period of 12 months } \\
\hline & Winner & Loser & Momentum & Winner & Loser & Momentum & Winner & Loser & Momentum \\
\hline
\end{tabular}

Panel A: Ranking period of 3 months

Portfolio position retained (\%)

\begin{tabular}{|c|c|}
\hline$L=10 \%$ & 3.13 \\
\hline$L=20 \%$ & 4.60 \\
\hline$L=50 \%$ & 6.72 \\
\hline$L=80 \%$ & 10.11 \\
\hline$L=90 \%$ & 11.37 \\
\hline
\end{tabular}

$\begin{array}{rr}3.44 & 4.95 \\ 5.66 & 7.27 \\ 6.30 & 9.68 \\ 10.88 & 14.04 \\ 12.39 & 16.49\end{array}$

4.34

3.91

6.90

10.61

12.26

Total trading costs based on actual turnover

$\begin{array}{llll}L=10 \% & 0.39 & 0.55 & 0.94 \\ L=20 \% & 0.43 & 0.65 & 1.08 \\ L=50 \% & 0.61 & 0.95 & 1.56 \\ L=80 \% & 0.86 & 1.27 & 2.13 \\ L=90 \% & 0.99 & 1.45 & 2.43\end{array}$

Panel B: Ranking period of 6 months

Portfolio position retained (\%)

\begin{tabular}{|c|c|}
\hline$L=10 \%$ & 9.29 \\
\hline$L=20 \%$ & 16.96 \\
\hline$L=50 \%$ & 20.85 \\
\hline$L=80 \%$ & 29.84 \\
\hline$L=90 \%$ & 33.54 \\
\hline
\end{tabular}

Total trading costs based on actual turnover

$\begin{array}{llll}L=10 \% & 0.37 & 0.53 & 0.90 \\ L=20 \% & 0.38 & 0.59 & 0.97 \\ L=50 \% & 0.52 & 0.85 & 1.37 \\ L=80 \% & 0.68 & 1.07 & 1.75 \\ L=90 \% & 0.76 & 1.19 & 1.94\end{array}$

Panel C: Ranking period of 12 months

Portfolio position retained (\%)

$\begin{array}{lll}L=10 \% & 12.64 & 18.12 \\ L=20 \% & 19.18 & 25.52 \\ L=50 \% & 31.14 & 34.01 \\ L=80 \% & 43.62 & 46.31 \\ L=90 \% & 48.59 & 51.74\end{array}$

0.10
0.12
0.17
0.24
0.28

0.23

0.26

Total trading costs based on actual turnover

\begin{tabular}{|c|c|c|c|c|c|c|c|c|c|}
\hline$L=10 \%$ & 0.35 & 0.49 & 0.84 & 0.19 & 0.33 & 0.52 & 0.09 & 0.24 & 0.33 \\
\hline$L=20 \%$ & 0.36 & 0.55 & 0.91 & 0.20 & 0.38 & 0.58 & 0.10 & 0.25 & 0.36 \\
\hline$L=50 \%$ & 0.45 & 0.77 & 1.21 & 0.26 & 0.53 & 0.79 & 0.14 & 0.34 & 0.48 \\
\hline$L=80 \%$ & 0.55 & 0.93 & 1.48 & 0.35 & 0.67 & 1.02 & 0.19 & 0.43 & 0.63 \\
\hline$L=90 \%$ & 0.59 & 1.02 & 1.61 & 0.39 & 0.76 & 1.15 & 0.22 & 0.49 & 0.71 \\
\hline
\end{tabular}


Table 3 - Estimates of Net Monthly Returns on Low-Cost Momentum Strategies

The table reports annual average net returns (\%) on low-cost momentum strategies based on full and actual turnovers. The low-cost momentum strategy buys the $L \%$ of winners and short sells the $L \%$ of losers with the lowest total costs (measured as quoted spread plus commission). When actual turnover is measured, stamp duty on purchases $(0.5 \%$ per purchase) and short selling costs for losers $(1.5 \%$ per year) are also considered as part of trading costs. $t$-statistics in parentheses.

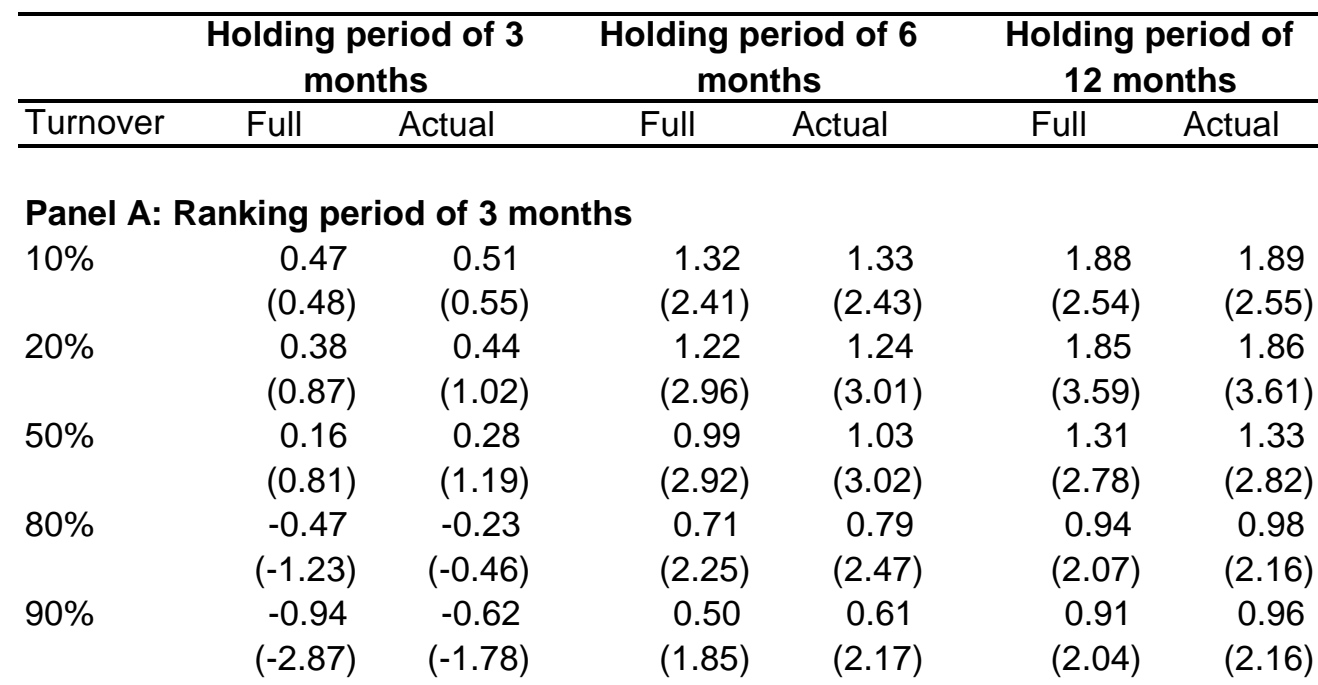

Panel B: Ranking period of 6 months

$\begin{array}{lcccccc}10 \% & 1.04 & 1.12 & 1.85 & 1.86 & 1.78 & 1.79 \\ & (1.33) & (1.47) & (3.01) & (3.04) & (2.40) & (2.41) \\ 20 \% & 0.84 & 0.99 & 1.42 & 1.44 & 1.24 & 1.25 \\ & (1.85) & (2.19) & (3.19) & (3.23) & (2.16) & (2.18) \\ 50 \% & 0.54 & 0.83 & 1.21 & 1.26 & 1.01 & 1.03 \\ & (2.14) & (2.98) & (3.50) & (3.65) & (2.17) & (2.22) \\ 80 \% & -0.06 & 0.51 & 0.94 & 1.02 & 0.66 & 0.70 \\ & (0.19) & (1.89) & (2.67) & (2.89) & (1.49) & (1.58) \\ 90 \% & -0.44 & 0.30 & 0.73 & 0.84 & 0.60 & 0.65 \\ & (-1.05) & (1.23) & (2.14) & (2.45) & (1.37) & (1.47)\end{array}$

Panel C: Ranking period of 12 months

$\begin{array}{lcccccc}10 \% & 1.27 & 1.39 & 2.13 & 2.16 & 1.63 & 1.63 \\ & (3.12) & (3.34) & (4.09) & (4.13) & (2.47) & (2.48) \\ 20 \% & 1.36 & 1.55 & 1.48 & 1.52 & 1.57 & 1.59 \\ & (4.06) & (4.56) & (3.73) & (3.82) & (2.94) & (2.97) \\ 50 \% & 0.69 & 1.09 & 1.10 & 1.18 & 1.32 & 1.34 \\ & (2.99) & (4.37) & (3.93) & (4.17) & (3.59) & (3.64) \\ 80 \% & 0.00 & 0.76 & 0.85 & 1.02 & 1.08 & 1.12 \\ & (0.60) & (3.20) & (3.02) & (3.56) & (3.02) & (3.14) \\ 90 \% & -0.36 & 0.62 & 0.70 & 0.93 & 0.96 & 1.01 \\ & (-0.66) & (2.77) & (2.54) & (3.28) & (2.65) & (2.79)\end{array}$



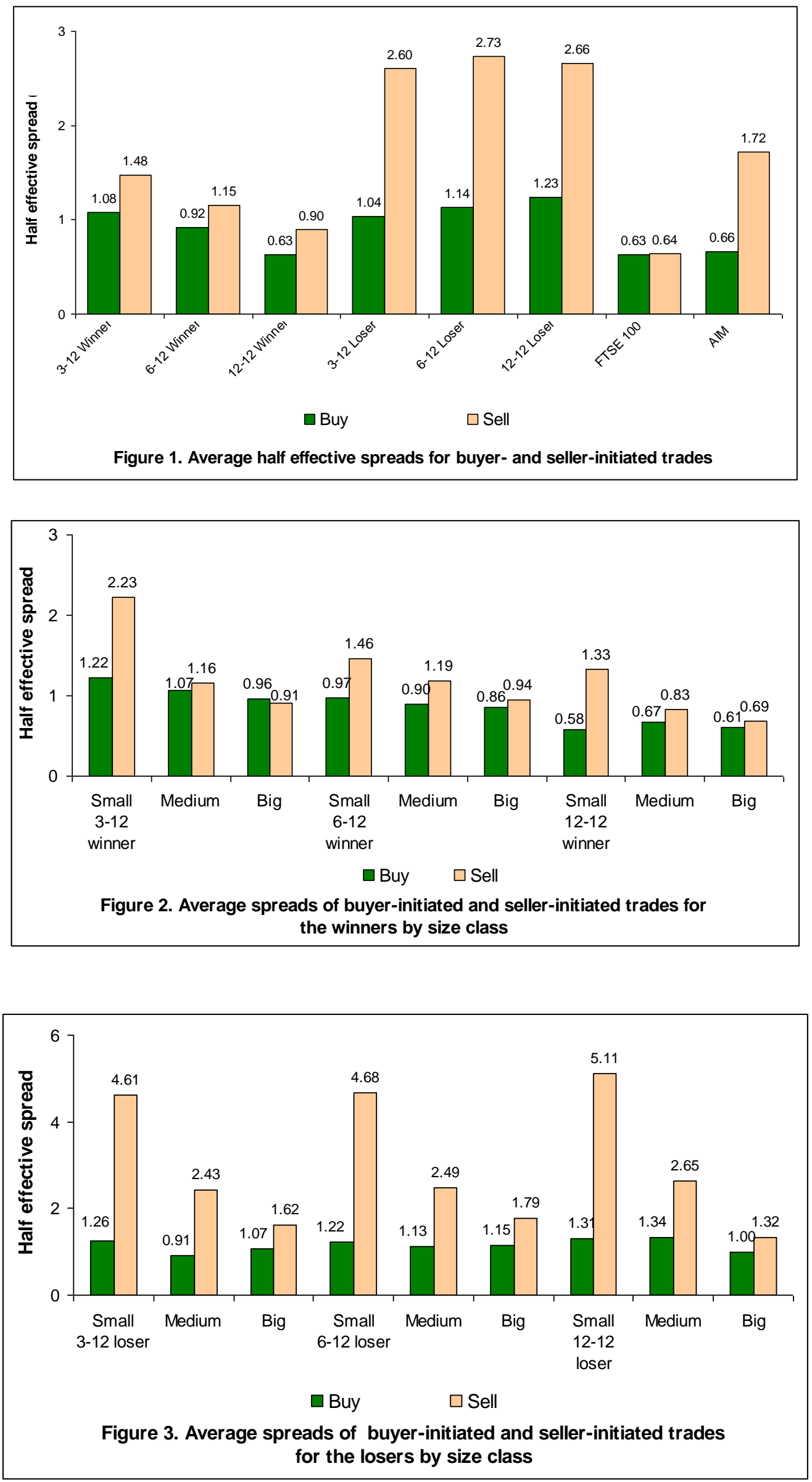